The University of San Francisco

USF Scholarship: a digital repository @ Gleeson Library |

Geschke Center

Hospitality Management

School of Management

2007

\title{
Internet Recruiting in the Cruise Industry
}

Michelle Millar

University of San Francisco, mmillar@usfca.edu

Follow this and additional works at: http://repository.usfca.edu/hosp

Part of the Hospitality Administration and Management Commons

\section{Recommended Citation}

Millar, Michelle, "Internet Recruiting in the Cruise Industry" (2007). Hospitality Management. Paper 12.

http://repository.usfca.edu/hosp/12

This Conference Proceeding is brought to you for free and open access by the School of Management at USF Scholarship: a digital repository @ Gleeson Library | Geschke Center. It has been accepted for inclusion in Hospitality Management by an authorized administrator of USF Scholarship: a digital repository@ Gleeson Library | Geschke Center. For more information, please contact repository@usfca.edu. 
Research Proceedings of the Las Vegas International Hospitality and Convention Summit, 2007, Las Vegas, Nevada

\section{INTERNET RECRUITING IN THE CRUISE INDUSTRY}


Research Proceedings of the Las Vegas International Hospitality and Convention Summit, 2007,

\title{
INTERNET RECRUITING IN THE CRUISE INDUSTRY
}

\author{
Michelle Millar, M.S., PhD Student \\ University of Nevada, Las Vegas \\ 702-343-3093 \\ 702-446-8062 Fax \\ millarm@unlv.nevada.edu
}

\begin{abstract}
The cruise line industry is expanding rapidly. Recruitment within the industry will be an endless task and the cruise lines will need to explore every avenue possible to recruit new employees for each new contracted ship. The purpose of this study, therefore, is to examine the website of each major cruise line to determine if they are utilizing their website to recruit employees. In total, 33 attributes relating to e-recruiting method, function, content, and job search tools, were analyzed. The results of the content analysis revealed that, although the cruise lines are using e-recruiting methods, they are not using the methods to their fullest capability.
\end{abstract}

Key Words: cruise; internet recruiting; e-recruiting; corporate website; content analysis 
Research Proceedings of the Las Vegas International Hospitality and Convention Summit, 2007, Las Vegas, Nevada

\section{INTRODUCTION}

The cruise line industry is expanding rapidly. In 2005, approximately 9.6 million U. S. passengers took a cruise of 2 days or longer. In the next 3 years, that number has the potential to reach 20 million people. The cruise lines are rushing to meet the expected demand by contracting for new and bigger ships. Between 2006 and 2010 it is expected that 26 new ships will be added to North America's fleet of ships, resulting in a total of 300,000 beds. (Cruise Lines International Association, 2006). With the addition of so many new ships, the cruise line industry will be in great need of employees.

Recruitment within the industry will be an endless task. A ship with a capacity of 2000 people typically has a staff of 950. The cruise line industry will need to explore every avenue possible to recruit new employees for each new ship. Traditional recruitment methods have included placing advertisements in the newspaper, working with employment agencies, or simply waiting for someone to walk in the door to fill out an application. All of those methods are time consuming and expensive. On the other hand, internet recruiting is not. Internet recruiting, as with the cruise line industry, has grown greatly in the past several years. In 2002, approximately 52 million Americans alone searched for jobs on the internet, representing a $60 \%$ increase from 2000 (Boyce and Rainie, 2002). It is an easy and affordable way for employers to reach a large amount of potential employees. Since many cruise line employees hail from all over the world, the internet is a very convenient way for a cruise line to reach and recruit them. Potential employees can find available jobs with different cruise lines either directly through a cruise line's website, or through other general internet recruitment sites such as www.Monster.com, or through industry-specific recruitment websites such as www.hcareers.com. 
Research Proceedings of the Las Vegas International Hospitality and Convention Summit, 2007, Las Vegas, Nevada

The purpose of this study is to determine if major cruise lines in the United States are using the internet as a recruitment tool. The specific research questions are:

1. Are cruise lines using their own corporate websites as recruitment tools?

2. If they are, what recruitment functions and tools are utilized, and to what degree are they used as compared to other corporations?

3. Do cruise lines post job openings on third party websites, instead of, or in addition to, their own websites?

The website of each major cruise line will be examined to determine if the cruise line is utilizing the site to recruit employees. A content analysis will be used to find out, for example, whether the websites provide information about what jobs are available, job descriptions, job requirements, and the ability to apply online. In addition, the content of available corporate information such as benefits, culture, or diversity will be analyzed. The study will also focus on the availability of cruise line jobs on other employment websites such as www.Monster.com, www.hcareers.com, or other similar employment recruitment websites.

\section{LITERATURE REVIEW}

\section{Traditional Recruiting vs. Internet Recruiting}

Traditional job search methods have typically been very people, paper, and time intensive. For example, it is not uncommon for job seekers to have printed and mailed dozens of résumés to the companies they wish to work for, whether there is an opening at that company or not. The companies in turn would send a letter of acceptance for an interview, or a letter of rejection. In addition to all of the paper used in this process, much time has also gone by (Kuhn \& Skuterud, 2000). 
Research Proceedings of the Las Vegas International Hospitality and Convention Summit, 2007, Las Vegas, Nevada

Another traditional method that is time consuming is contacting friends and relatives to see if they had or knew of any job vacancies. Companies have come to depend on such methods, referrals, in addition to walk-ins. Walk-ins include job seekers that visit the companies they wish to work for in order to drop off a résumé and to discover what jobs are available. The hope is that the company will have an opening that is suited to the applicant's skills (Koong, Liu \& Williams, 2002). A similar method is making telephone calls, or cold calls, to inquire about job openings.

Lee (2005) outlines the traditional method of recruitment as seen from the company's point of view:

The traditional recruiting process consists of the following ... phases: identification of hiring needs; submission of job requisition and approval; job posting; submission of job applications; screening of résumé/application; interviewing; pre-employment screening; and job offer and employment contract. Both hiring managers and recruiters rely on hardcopy documents and conventional delivery mechanisms to complete the recruiting process. (p. 58)

This traditional process outlines exactly how people, paper, and time-intensive the entire recruitment procedure can be.

Internet recruiting, on the other hand, is different. Recruiting on the internet is also known as "online recruiting", "web-based recruiting", and "e-recruiting". All of these terms are used inter-changeably. What, though, do they all mean? Lee (2005) defines internet recruiting as "practices and activities carried on by the organization that utilizes a variety of electronic means to fill open positions effectively and efficiently" (Lee, 2005, p. 58). At the end of 2006, online internet recruiters were spending more money in online job postings than in any other medium. 
Research Proceedings of the Las Vegas International Hospitality and Convention Summit, 2007, Las Vegas, Nevada

\$5.9 billion was spent online versus \$5.4 for newspaper ads (Borrell Associates, 2006).

Considering that the first companies to start recruiting online did so only around the 1990's, those numbers are staggering. Today $79 \%$ of all Fortune 500 companies have a direct link from their corporate websites to employment information (Taleo Research, 2005). Fully 90\% of large U. S. companies are recruiting via the internet (Cappelli, 2001).

According to Lee (2005), there are five stages that companies go through in the internet recruitment process for their own corporate website. The first stage is simply listing available jobs on the website, and providing contact information. The second stage includes stage one, as well as the ability for job candidates to search for jobs on the website. In stage three, information about job openings is forwarded on to the potential candidate. In other words, the company sends information to the candidate based on criteria that the candidate has predetermined. This eliminates the need for the candidate to continuously check the website for new job postings. The fourth stage, which incorporates all of the features in the previous three stages, provides a decision support system for candidates. Such a system provides selfassessment tools and pre-screening capabilities. Finally, in stage five, the entire process is streamlined in particular to enhance the relationship with the candidate. The idea is to promote a “two-way, long-term relationship between employers and prospective employees" (Lee, 2005, p. $61)$.

In addition to using their own corporate websites, companies are also using third party websites such as Monster.com or Hotjobs.com. These sites enable job seekers to use search engines to find several jobs that they might be interested in at more than one company. The job seeker can then post a résumé, which the search engine then forwards on to the company advertising the job position (Braddy, Thompson, Wuensch, \& Grossnickle, 2003). This process 
Research Proceedings of the Las Vegas International Hospitality and Convention Summit, 2007, Las Vegas, Nevada

can save the company time because the third party websites manage the database of résumés. The largest online employment referral service for employers, recruiters, and job seekers, Careerbuilder.com, is the largest generator of revenue for the market (www.careerbuilder.com, n.d.). The job recruitment sites typically charge employers to post jobs on their sites but do not charge job seekers. Monster.com is also one of the largest no-fee referral companies in the world (Salway, 2000). Hotjobs.com, a subsidiary of Yahoo!, offers similar services as both Monster.com and Careerbuilder.com. These three recruitment companies are the three most widely recognized in the internet recruiting industry (Tong \& Sivanand, 2005).

In addition to general recruitment websites, such as those just mentioned, there are also niche websites that cater to specific industries. For example, in the hospitality industry, the most well known recruitment site is hcareers.com. Hcareers.com posts jobs for hotels, restaurants, and retail and currently has over 75,000 job postings and 900,000 new visitors every month (hcareers.com, n.d.). Hospitalityonline.com is another well-known industry-specific site. In addition to posting jobs for job seekers to browse, the website also provides a career management toolkit. For the cruise line industry, there is one stand out recruitment website, which is cruiseshipjob.net. Cruiseshipjob.net differs from other recruitment websites, however, in that job seekers must pay a fee to have their résumé submitted to the cruise lines that are hiring.

In 2002, fifty-two million Americans were online searching for employment on either corporate career websites or third party career websites. On any given day, 4 million people do so. Of those people that are unemployed, $51 \%$ of them have internet access with one-tenth of them searching online for jobs on a typical day (Boyce \& Rainie, 2002). The bottom line is that the internet provides a huge recruitment market for companies, and many people, whether they 
Research Proceedings of the Las Vegas International Hospitality and Convention Summit, 2007, Las Vegas, Nevada are the employer looking for employees, or job seekers looking for jobs, are taking advantage of it.

\section{Internet Recruiting - Advantages}

There are several advantages to internet recruiting. One of them is cost savings (Koong, Liu, \& Williams, 2002, Munger, 2002, Cappelli, 2001, Pollitt, 2005, Lee, 2005, \& Taleo Research, 2005). For example, since Nike introduced internet recruitment into their Europe, Middle East, and Asia headquarters, they estimate a 54\% reduction in their recruitment costs (Pollitt, 2005). Compared to the traditional methods of recruiting via classified advertisements in the newspaper, internet recruitment is considerably less expensive. Forrester Research estimates that the traditional method of advertisement costs $\$ 1383$, whereas posting the job on the internet averages between \$152-\$183 (Lee, 2005; Koong et al., 2002). A boost to this cost savings is the efficiency gained by recruiting online. Résumés are processed much faster and job openings filled more quickly. Fortune 500 companies claim that they have shaved, on average, 6 days off of their hiring cycles (Cappelli, 2001). Nike reduced its hiring cycle by 20 days (Pollitt, 2005) while Dow Chemical reduced its cycle from 90 days down to 34 days (Lee, 2005). There is no doubt, as is evidenced by the number of U. S. companies using internet recruitment, that cost and time are important advantages.

Another important advantage is that the internet provides a market for employers that they may not otherwise be able to reach. For example, a marketing firm in a small town may need a new president. By recruiting online, that firm can post their job for anyone in the country, or anyone in the world, to see. It is not stuck simply placing help wanted ads in local newspapers. That firm now has the potential to reach a larger audience and most likely a larger pool of 
Research Proceedings of the Las Vegas International Hospitality and Convention Summit, 2007, Las Vegas, Nevada

talented candidates. In essence recruitment on the internet is "unconstrained by geography" (Cappelli, 2001).

\section{Internet Recruiting - Disadvantages}

Along with the advantages of internet recruiting come some disadvantages. One such disadvantage is the sheer number of résumés that employers receive. The onslaught of résumés after posting an available job opening can make it even more difficult to find qualified job applicants. When HR managers posted jobs previously in newspapers, for example, a few résumés trickled in at a time. Today, with most recruitment or corporate sites enabling job applicants to email résumés, HR managers are inundated, especially in the days immediately following the original posting date. To combat this potential problem, a company must have internal procedures and practices in place to handle the online application process (Starcke, 1996).

Another disadvantage is that the internet can make it difficult to find "passive job seekers" (Starcke, 1996). The question becomes how a company finds someone that may be interested in a specific job at a specific company but is not actually seeking employment or looking on recruitment websites. Another question that is raised is whether a computer can be trusted to evaluate a person's skills and abilities - a task traditionally done by humans (Smith \& Rupp, 2004). As Smith and Rupp (2004) point out “...the idea of having computers assess a person’s skills and determine whether the candidate should be interviewed seems inconsistent with what the human resources profession is all about - people" (p. 69).

Internet recruiting also raises concerns for many about privacy and security. Employment and salary history, contact information, education, and references are posted by applicants when either applying for a specific job or searching for jobs in general (Smith \& Rupp, 2004). This 
Research Proceedings of the Las Vegas International Hospitality and Convention Summit, 2007, Las Vegas, Nevada

information is then "out there" for anyone to access. In addition to privacy, other concerns are that not everyone may have access to the internet. Although many people in the United States have access to the internet that may not necessarily be the case in the rest of the world.

\section{Internet Recruiting in the Hospitality \& Tourism Industry}

Although there is no literature that discusses internet recruiting in the cruise line industry, internet recruiting in the hotel or hospitality industry is fairly well discussed, especially in the trade journals. Rushmore (2000) discusses the growth and popularity of specific service-job related recruitment websites for the hospitality industry, while the article To Become Critical ...(2001) touts the importance of the internet in hiring practices in the foodservice industry. Blank (2001) also emphasizes the importance for hotels to recruit on the internet because the industry faces a shortage of qualified workers. Recruiting via the internet is one possible solution to finding qualified employees. Berta (2000) suggests that recruiting online is now common practice for hotels and restaurants and has become very popular for hospitality companies. Other authors argue that, while internet recruiting is important, and perhaps is common, it is not effective in finding or attracting hourly workers, which are a large part of the hospitality industry (Chollet, 2001; Nations Restaurant News, 1999).

\section{METHODOLOGY}

Content analysis was used to analyze the websites of nineteen cruise line companies. There are many definitions of content analysis (Kassarjian, 1977). The following definition provided by Kerlinger (1964) is the most comprehensive:

Content analysis, while certainly a method of analysis, is more than that.

It is... a method of observations. Instead of observing people's behavior directly...the investigator takes the communications that people have 
Research Proceedings of the Las Vegas International Hospitality and Convention Summit, 2007, Las Vegas, Nevada

produced and asks questions of the communications. (p. 544)

It is a marketing research technique used to provide new insights, information and a representation of facts. The traditional domain of content analysis is mass communication, which includes radio, television, magazines, newspapers, and today, computers and the internet. The form of communication in this study is the websites of nineteen cruise lines. The researcher is using content analysis to determine what information the websites of those nineteen cruise lines obtains in relation to employment. Specifically, content analysis was used to study how and if nineteen cruise lines are using their own websites to promote employment. Questions about the content in the website communication, the employment information, as Krelinger (1964) recommends above, are what drive the analysis.

\section{Participants}

Each cruise line chosen for analysis in this study is a member of the Cruise Lines International Association (CLIA). CLIA, formed in 1975, is the world's largest cruise line association (CLIA, 2006). CLIA has 21 members, which represent $97 \%$ of the cruise line capacity that is marketed in the United States. Of the 21 CLIA members, 19 were chosen for analysis. Two were discarded because they do not yet have operating ships or websites. At the end of 2005, the nineteen cruise lines had a combined total of 146 ships, with approximately 220,000 beds (CLIA, 2006). All operate cruises throughout the world with trip lengths averaging 7 days (CLIA, 2006). The cruise lines use CLIA as an external marketing organization, the major one of its kind in the cruise line industry.

$<$ Insert Table One here $>$ 
Research Proceedings of the Las Vegas International Hospitality and Convention Summit, 2007, Las Vegas, Nevada

\section{Internet site evaluation form}

Each website was analyzed based on employment website characteristics developed by both Lee (2005), and Cober, Brown, and Levy (2004). Lee (2005) conducted a content analysis of Fortune 100 company's websites to determine how they were using the internet as a recruitment tool. He developed four categories for analysis: (a) internet recruiting methods, (b) job search tools, (c) job application tools, and (d) corporate information. E-recruiting methods include what type of website the company used, such as corporate career site, or third party website. Job search tools identified whether the website provided the capability for users to search for jobs by category, job location, or job type (part/full-time). Job application tools were the means by which applicants could apply for jobs, i.e. online application, email, fax, or résumé submission. The corporate information category included relevant information about the company itself, benefits, compensation, or diversity, to name a few.

Cober et al.'s (2004) study, took a similar approach by analyzing Fortune magazine's “Best Companies to Work For." The primary purpose of their study was to develop a methodology for assessing corporate recruitment websites. Cober et al. divided internet recruitment practices, as presented on the corporate websites, into three categories, which are form, function, and content (Cober et al., 2004). The form category includes the attractiveness of the website, color, sound, images, or overall aesthetics of the webpage. Function refers to the usability of the employment website. The content category is very similar to Lee's (2005) corporate information category in that it includes information about the work environment, training opportunities, and other general information about the company. The primary difference between Cober et al. (2004), and Lee, (2005), is that Lee did not analyze the functionality or form of the websites. He was primarily interested in simply what information, if any, the websites provided about employment. This 
Research Proceedings of the Las Vegas International Hospitality and Convention Summit, 2007, Las Vegas, Nevada

study takes the same approach, but, at the same time, does incorporate some of Cober et al.'s guidelines for assessing content.

The website evaluation form for the present study consisted of four sections. The first section, incorporated from Lee (2005), was titled e-recruiting methods and consisted of four specific attributes. The attributes focused on where on the website the cruise line promoted jobs, e.g. via direct link from the home page to an employment section of the site or via an indirect link to employment information. An indirect line accessed jobs by way of, for example, the "about our company" link. The other two attributes were whether the cruise line posted jobs on either third party job boards or on cruise line industry job boards. If they did, it was also noted whether there was a hyperlink from the cruise site to the third party, or industry site.

The second category, job application tools, also taken from Lee's (2005) study, included how potential applicants could apply for a specific job. The seven attributes included, to name a few, online application, résumé attachment, or email, mail, or fax an application.

The third category was primarily taken from Cober et al.'s (2004) study because the attributes were more specific than in Lee's study. In total, 18 attributes were included in this section. The attributes incorporated information about the organization itself, and compensation (i.e. salary, vacation, health insurance). This category was titled content.

Finally, the last category, job search tools, includes ways in which potential applicants can search for jobs within the website itself, e.g. job location, or job type. In total, 33 attributes were assessed for each website. See Appendix A for a copy of the internet site evaluation form.

\section{Data Collection}

Two raters accessed the website of each cruise line by simply typing in the name of the cruise line as the website address. All website addresses were the actual name of the cruise line. 
Research Proceedings of the Las Vegas International Hospitality and Convention Summit, 2007, Las Vegas, Nevada

After the initial analysis of the cruise line website, cruise jobs were searched for on the third party websites www.Monster.com, www.hotjobs.com, and www.careerbuilder.com by each rater. Keywords such as "cruise jobs", and the cruise line name were used to search under the job category of hospitality/tourism jobs, as well as a general category search. The same process was repeated for the industry recruitment sites www.hcareers.com and www.cruiseshipjob.net. Neither the third party recruitment sites, nor the industry recruitment sites were assessed for the specific attributes related to job information. The researchers focused solely on those attributes as listed on the cruise lines' actual websites. Once all websites were assessed, the data collection sheets used for analysis were compared between raters. Any discrepancies were discussed and adjustments made if necessary.

\section{RESULTS}

\section{E-recruiting methods}

Of the 19 cruise lines, ten of them provided a direct link from their home page to employment information. Six provided the link indirectly via "about our company", while three cruise companies provided no information at all about employment on their site. In addition to posting jobs on their own sites, most of the cruise companies also posted jobs on both third party job boards $(57.9 \%)$ as well as industry job boards $(52.6 \%)$. Nine of the cruise lines posted jobs on www.monster.com, seven posted jobs on www.careerbuilder.com, and three posted jobs on www.hotjobs.com. The industry recruiting website www.cruiseshipjobs.net proved the most popular of the industry sites with eight of the cruise lines posting jobs there. Six cruise lines had job postings on www.hcareers.com. Very few of the cruise lines, however, provided any hyperlinks to either the third party $(10.5 \%)$ or industry $(5.3 \%)$ recruitment websites. In total, 
Research Proceedings of the Las Vegas International Hospitality and Convention Summit, 2007, Las Vegas, Nevada sixteen cruise lines provided employment information, whether directly or indirectly, on their corporate websites.

\section{Job application tools}

In the job application tools category, which includes how job applicants may apply for jobs, there was no significant application method that the majority of the cruise lines used. Exactly $50 \%$ of the companies that provided direct or indirect links to employment information provided the ability for applicants to apply directly online using an online application tool. Seven (43.8\%) of the cruise lines required that applicants download, fill out and email the application, or email a résumé as an attachment (43.8\%). Mailing in an application was the preferred method $<$ Insert Table Two here $>$

for six cruise lines (37.5\%) while fewer preferred faxed applications (12.5\%). Very few (2) of the cruise companies provided an online résumé building tool, nor did they try to prescreen applicants.

\section{Content}

The content category contained the most attributes. Beginning with information about compensation, 15 of the 16 cruise lines provided no salary information. The majority of the lines also did not provide any detail about vacation plans $(75 \%)$, healthcare $(75 \%)$, dental care $(75 \%)$ or investment $(401 \mathrm{k})$ opportunities $(81.3 \%)$. Those that did provide compensation information only did so in a very general sense.

A list of available jobs was posted on 12 of the 16 websites, with all of them posting the job description and requirements. None of the companies described what a typical work day might be like with their cruise line, but three did provide general descriptions of working either on the ship or in the land-based management offices. Two cruise lines did have, however, a section of 
Research Proceedings of the Las Vegas International Hospitality and Convention Summit, 2007, Las Vegas, Nevada

frequently asked questions about working for a cruise company. The cruise line's websites also shared both the value/vision/culture $(56.3 \%)$ and mission statements $(37.5 \%)$ with potential applicants. Only $25 \%$ of the cruise lines gave any information of advancement opportunities or training opportunities. Less than $10 \%$ provided details about company diversity, employee testimonials, tips for résumé writing, or tips for interviews.

\section{Job Search Tools}

The cruise lines did not take advantages of job search tools. Seventy five percent of them did not have any sort of job search capability (job category, keywords, job location), and only three provided the ability to search by profession (18.8\%). For a summary of analyzed attributes, please see Table 2 .

\section{DISCUSSION}

The 16 cruise lines performed well overall by using direct or indirect links to employment information within their websites. They also performed well by providing lists of available jobs on their sites. All of the cruise lines listing their available jobs had them separated into shipboard jobs and corporate or land-based jobs, with descriptions of each job. Several of the cruise lines also took advantage of third party and industry job boards. In summary, they preformed well in the e-recruiting method category, with some overlap into the content category. However, this does not appear to be the case with the other key aspects of internet recruiting.

In the job application tools category, only half of the cruise companies provided an online application, and a surprisingly large number of them required that applicants mail in applications or résumés in order to apply for jobs. That process seems counterintuitive to internet recruiting and may even hinder people from applying. Also, as mentioned previously, one of the advantages of internet recruiting is that it saves time. Requiring applicants to mail applications 
Research Proceedings of the Las Vegas International Hospitality and Convention Summit, 2007, Las Vegas, Nevada

negates that advantage. The fact that the cruise lines are not using their websites to their fullest potential portrays an image that the cruise line may not really be up to speed, or hip, with technology. It may also send the image that they are not organized well enough to accept applications online, or vie email. As Braddy et al. (2003) explain about company image, “...being successful when attracting applicants entails maintaining a favorable recruitment image; therefore, organizations should attempt to relay information in ways that enhance their recruitment images" (p. 374). The cruise lines are not taking the opportunity to attract employees by portraying a professional image.

The cruise lines also performed poorly overall in the content category. In essence, this section should contain the information that the cruise line can use to completely sell itself to potential employees. While job lists and descriptions were provided, no other information, for the majority of the cruise lines, was provided. For example, working on a ship is presumably unlike most other jobs, yet none of the cruise lines provided any description of what a typical day at work might be like. If anyone is to apply for a job on a ship, they should be made aware of the ins and outs of working on a ship. According to Raub \& Street (2006), this is known as realistic recruitment in the cruise industry. Realistic recruitment could easily be part of internet recruitment by either posting employee testimonials or short video clips of life on board a ship on the cruise line website.

It is understandable that salary information not be posted on websites because it may vary by individual. However, even some small indication of what the salary could be, would be useful. Potential job candidates, especially those completely new to the cruise industry, will have no idea where salary may start. The same may be said of other benefits. General information, such as whether medical/dental benefits are even offered, will educate job 
Research Proceedings of the Las Vegas International Hospitality and Convention Summit, 2007, Las Vegas, Nevada

candidates about the cruise company. At the very least, the cruise lines could provide contact information so that people could request more information about benefits.

In the job search category, the cruise lines performed the worst overall. Seventy five percent of them did not provide potential employees with a way to search the cruise site for available jobs. Providing job search tools enables job candidates to identify specifically what type of job they are looking for. This eliminates the need to sift through all posted jobs. With said that, however, the number of posted available jobs for each cruise line was limited so perhaps they feel that job search tools are not necessary.

Compared with Lee's (2005) study, which found that Fortune 100 companies are in Stage 4 (decision support e-recruiting) of the internet recruiting process, the cruise industry is lagging behind. The cruise lines are still in the stages of simply delivering information (Stage 1), with some cruise lines creeping into Stage 2. In addition to being behind in the internet recruitment stages, the cruise lines are also behind in specific attributes. For example $83 \%$ of the Fortune 100 companies provided an online application tool, while only $50 \%$ of the cruise lines did. Likewise, almost $84 \%$ of the cruise lines had employment information on their corporate websites, while $94 \%$ of the Fortune 100 companies did. The same results can be said of virtually all attributes. Essentially, the cruise lines are not taking advantage of using their corporate website as recruitment tools as well as the Fortune 100 companies are.

\section{RECOMMENDATIONS AND LIMITATIONS}

There is limited academic literature in the hospitality industry about internet recruitment, in particular about how well companies use their sites to promote employment. Therefore, this study had to draw from other disciplines such as marketing, consumer research, and information technology, to gather relevant literature. To alleviate this problem for future research, more 
Research Proceedings of the Las Vegas International Hospitality and Convention Summit, 2007, Las Vegas, Nevada

studies focusing on other segments of the hospitality industry (hotel, food and beverage, or club management) could be conducted to both expand the available literature and use the results to compare with, and validate, the present study.

The sample for this study is small and only focuses on those cruise lines that are members of the Cruise Line International Association. There are other cruise lines within the United States that are not members of CLIA, and there are other cruise lines throughout the rest of the world that are not members. Therefore, generalization of the results of the present study to other cruise lines would not be recommended. A larger study encompassing all cruise organizations would prove interesting as a comparison to the CLIA members.

Technology changes rapidly and companies continue to adapt to it. A consequence of that is that the cruise lines could change the make-up of their career websites tomorrow, thus making it difficult to obtain the same data collected for this study.

Future studies may include a follow up study that analyzes the interactivity, functionality, navigation, and design of cruise lines' websites. This study focused only on the content of the websites but further research into how the websites are perceived by users and how the websites compare with other hospitality industry corporate websites may help to define a methodology that may be incorporated and used for all sectors of the hospitality and tourism industry.

\section{CONCLUSION}

"Sixty percent of all Internet hires come through a company’s own website" (Forster, 2003, p. R8). Thus, the importance of having the content, or information that applicants are looking for. Currently, it appears that the major cruise lines that are marketing in the United States may not have yet realized this importance. The results of this study indicate that cruise lines are not taking full advantage of the internet recruiting capabilities that are available to them, at least not 
Research Proceedings of the Las Vegas International Hospitality and Convention Summit, 2007, Las Vegas, Nevada

as well as the Fortune 100 companies are. They need to develop better internet recruiting systems if they are to compete with other companies that are both within the cruise industry, and in other industries.

With the cruise line industry growing so rapidly, it is essential that they do everything that they can to recruit new employees. Internet recruiting is but one part of the recruitment process, but it is oftentimes the first contact that a potential employee may have with the company. If the first impression is not a favorable one, the potential employee may move on to another company's website.

\section{References}

Berta, D. (2000). Industry makes online recruiting part of standard hiring procedures. Nation's Restaurant News, 34(47), 8.

Borrell Associates (2006, December). 2007 outlook: online recruitment advertising (Pub. ID BAI1459759). Retrieved May 10, 2007 from

http://www.marketresearch.com/product/display.asp?productid=1459759\&xs=r\&SID=17122093 $-383630355-400097086 \&$ curr $=$ USD

Boyce, A., \& Rainie, L. (2002). PEW internet project data memo. Internet and American life project. Retrieved November 28, 2006 from http://www.pewinternet.org/pdfs/pip_jobhunt_memo.pdf.

Braddy, P., Thompson, L., Wuensch, K., \& Grossnickle, W. (2003). Internet recruiting: The effects of web page design features. Social Science Computer Review, 21(3), 374-385. Cappelli, P. (2001). Making the most of on-line recruiting. Harvard Business Review, 79(3), 512.

Careerbuilder (n.d.). About us. Retrieved May 8, 2007 from 
Research Proceedings of the Las Vegas International Hospitality and Convention Summit, 2007, Las Vegas, Nevada http://careerbuilder.com/share/AboutUs/default.aspx.

Chollet, M. (2001, January). Online recruiting. Club Management, 80(1), 60-65.

Cober, R., Brown, D., \& Levy, P. (2004). Form, content, and function: An evaluative methodology for corporate employment web sites. Human Resource Management, 43(1/2), 201-218.

Cruise Lines International Association (2006). Cruise industry overview. Marketing edition. Retrieved November 28, 2006 from http://www.cruising.org/press/overviewpercent202006/33.cfm.

Forster, S. (2003, September 15). Technology (a special report); the best way to recruit new workers. The Wall Street Journal, p. R8.

Hcareers (n.d.). Hcareers launches tools to help employers comply to OFCCP rule. Retrieved May 8, 2007 from http://www.hcareers.com/us/resourcecentr/pressreleases/hc20060206.aspx.

Kassarjian, H. (1977). Content analysis in consumer research. Journal of Consumer Research, $4,8-17$

Kerlinger, F. (1964). Foundations of Behavioral Research: educational and psychological inquiry. New York, N.Y.: Holt, Rinehart, and Winston.

Koong, S., Liu, L., \& Williams, D. (2002). An identification of internet job board attributes. Human Systems Management, 21, 129-135.

Kuhn, P. \& Skuterud, M. (2000). Job search methods: Internet versus traditional. Monthly Labor Review, 123(10), 3-11.

Lee, I. (2005). The evolution of e-recruiting: a content analysis of fortune 100 career web sites. Journal of Electronic Commerce in Organizations, 3(3), 57-68. 
Research Proceedings of the Las Vegas International Hospitality and Convention Summit, 2007, Las Vegas, Nevada

Munger, R. (2002). Technical communicators beware: The next generation of high-tech recruiting methods. IEEE, 45(4), 276-289.

Online recruiting ramps up: Internet technology gives hiring a new jolt (1999, November 1). Nation's Restaurant News, 33(44), 22.

Pollitt, D. (2005). E-recruitment gets the Nike tick of approval. Human Resource Management International Digest, 13(2), 33-35.

Raub, S. \& Streit, E. (2006). Realistic recruitment: An empirical study of the cruise industry. International Journal of Contemporary Hospitality Management, 18(4), 278-389.

Rushmore, S. (2000, June). "e-“" is for employment. Hotels, 40.

Salway, N. (2000). Web site review: www.provenresumes.com, www.careerlab.com/letters, www.monster.com. The Information Management Journal, 34(3), 49.

Smith, A. \& Rupp, W. (2004). Managerial challenges of e-recruiting: extending the life cycle of new economy employees. Online Information Review, 28(1), 61-74.

Starcke, A. (1996). Internet recruiting shows rapid growth. HR Magazine, 41(8), 61-66.

Taleo Research (2005). Trends in job application medium: A white paper by Taleo Research.

To become critical for f/s: Job-seekers turning to web as online recruiting grows. FoodService Director, 14(4), 6.

Tong, D. \& Sivanand, C. (2005). E-recruitment service providers review. Employee Relations, 27(1/2), 103-117. 


\section{Appendix A}

\section{Internet Site Evaluation Form}

Site URL:

Cruise Line:

Site Characteristics $(1=\mathrm{Yes}, 0=\mathrm{No})$

\section{E-Recruiting Method}

Corporate Career Website

Direct link to available jobs

Indirect link to available jobs (i.e.

Via "about our company")

Third party job board

Name

Hyperlink to site

Cruise Industry Job Board

Name

Hyperlink to site

\section{Function}

$\begin{array}{ll}1 \square & 0 \square \\ 1 & 0 \square\end{array}$

Online application tool

$1 \square \quad 0 \square$

$1 \square \quad 0 \square$

Résumé builder tool

$\begin{array}{ll}1 \square & 0 \square \\ 1 & 0 \square\end{array}$

Résumé attachment \& submission tool

Prescreen/Online interview

Other options to apply -

email application

post mail application

fax application $\begin{array}{ll}1 \square & 0 \square \\ 1 \square & 0 \square \\ 1 \square & 0 \square\end{array}$

\section{Content}

Compensation

Salary Information

Investment Plan

Vacation Plan

Healthcare information

Dental Care

Description of typical day at work

Description of workplace

List of "hot jobs"
Advancement Opportunity

$\begin{array}{ll}1 \square & 0 \square \\ 1 \square & 0 \square \\ 1 \square & 0 \square \\ 1 \square & 0 \square \\ 1 \square & 0 \square \\ 1 \square & 0 \square \\ 1 \square & 0 \square \\ 1 \square & 0 \square\end{array}$

Core value/vision/culture

Mission Statement

Diversity in company

Employee testimonials

Job Description/requirements

FAQ regarding career

Training

Tips for resume writing

Tips for interviews $\begin{array}{ll}1 \square & 0 \square \\ 1 \square & 0 \square \\ 1 \square & 0 \square \\ 1 \square & 0 \square \\ 1 \square & 0 \square \\ 1 \square & 0 \square \\ 1 \square & 0 \square \\ 1 \square & 0 \square \\ 1 \square & 0 \square \\ 1 \square & 0 \square\end{array}$

\section{Job Search Tools}

Existence of Job Search engine

By job category

By job location

By keywords

By profession

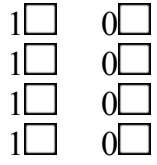


Research Proceedings of the Las Vegas International Hospitality and Convention Summit, 2007, Las Vegas, Nevada

Table One: Cruise Lines included in the study Cruise Line

\begin{tabular}{l}
\hline American Cruise Lines \\
Carnival Cruise Lines \\
Celebrity Cruises \\
Costa Cruises \\
Crystal \\
Cunard \\
Disney Cruises \\
Holland America \\
MSC Cruises \\
Norwegian Coastal Voyages \\
Norwegian Cruise Lines \\
Ocean Cruises \\
Orient Lines \\
Princess Cruises \\
Regent Seven Seas Cruises \\
Royal Caribbean \\
Seabourn \\
Silversea \\
Windstar
\end{tabular}


Research Proceedings of the Las Vegas International Hospitality and Convention Summit, 2007,

Table 2. Summary of the content analysis of cruise lines' websites

\begin{tabular}{|c|c|c|c|}
\hline Category & Attribute & $\#$ & $\%$ \\
\hline $\begin{array}{c}\text { E-recruiting } \\
\text { Methods } \\
\text { (19 cruise lines) }\end{array}$ & $\begin{array}{l}\text { Direct Link } \\
\text { Indirect Link } \\
\text { Third-party job board } \\
\text { Hyperlink to third party job board } \\
\text { Industry job board } \\
\text { Hyperlink to industry job board } \\
\text { Total }^{\mathrm{a}}\end{array}$ & $\begin{array}{c}10 \\
6 \\
11 \\
2 \\
10 \\
1 \\
40\end{array}$ & $\begin{array}{c}52.6 \\
31.6 \\
57.9 \\
10.5 \\
52.6 \\
5.3 \\
--\end{array}$ \\
\hline $\begin{array}{l}\text { Job Application Tools } \\
\left.\text { (16 } 16^{b} \text { cruise lines }\right)\end{array}$ & $\begin{array}{l}\text { Online application tool } \\
\text { Résumé builder tool } \\
\text { Résumé attachment/submission } \\
\text { Prescreen/online interview } \\
\text { Email application } \\
\text { Post mail application } \\
\text { Fax application } \\
\text { Total }^{\mathrm{c}}\end{array}$ & $\begin{array}{l}8 \\
2 \\
7 \\
2 \\
7 \\
6 \\
2 \\
34\end{array}$ & $\begin{array}{l}50.0 \\
12.5 \\
43.8 \\
12.5 \\
43.8 \\
37.5 \\
12.5 \\
--\end{array}$ \\
\hline $\begin{array}{c}\text { Content } \\
\text { (16 cruise lines) }\end{array}$ & $\begin{array}{l}\text { Compensation } \\
\text { Salary } \\
\text { Investment plan } \\
\text { Vacation plan } \\
\text { Healthcare information } \\
\text { Dental care } \\
\text { Description of typical day at work } \\
\text { Description of workplace } \\
\text { List of jobs } \\
\text { Advance opportunity } \\
\text { Core value/vision/culture } \\
\text { Mission statement } \\
\text { Diversity in company } \\
\text { Employee testimonials } \\
\text { Job description/requirements } \\
\text { FAX regarding career } \\
\text { Training } \\
\text { Tips for résumé writing } \\
\text { Tips for interviews } \\
\text { Total }\end{array}$ & $\begin{array}{c}1 \\
3 \\
4 \\
4 \\
4 \\
0 \\
3 \\
12 \\
4 \\
9 \\
7 \\
1 \\
1 \\
12 \\
2 \\
4 \\
0 \\
0 \\
71\end{array}$ & $\begin{array}{c}6.3 \\
18.8 \\
25.0 \\
25.0 \\
25.0 \\
0.0 \\
18.8 \\
75.0 \\
25.0 \\
56.3 \\
43.8 \\
6.3 \\
6.3 \\
75.0 \\
12.5 \\
25.0 \\
0.0 \\
0.0 \\
--\end{array}$ \\
\hline $\begin{array}{l}\text { Job Search Tools } \\
\text { (16 cruise lines })\end{array}$ & $\begin{array}{l}\text { Search by job category } \\
\text { Search by job location } \\
\text { Search by keywords } \\
\text { Search by profession }^{\text {Total }}{ }^{\mathrm{C}}\end{array}$ & $\begin{array}{c}4 \\
4 \\
4 \\
3 \\
15\end{array}$ & $\begin{array}{l}25.0 \\
25.0 \\
25.0 \\
18.0 \\
--\end{array}$ \\
\hline
\end{tabular}

Note.

${ }^{a}$ Cruise lines may provide more or less than one attribute therefore totals will not equal 19.

${ }^{\mathrm{b}}$ Only 16 of the 19 cruise lines provided employment information on their website, thus only 16 were further analyzed for job application tools, content, and job search tools. ${ }^{\mathrm{c}}$ Cruise lines may provide more or less than one attribute therefore totals will not equal 16. 